\title{
STRATEGI BAURAN PEMASARAN INTERNET DI PT. INDO INTERNET JAKARTA UNTUK MENINGKATKAN PANGSA PASAR
}

\author{
Sulaiman*) \\ leman.pamulang@gmail.com
}

\begin{abstract}
ABSTRAK
Jasa internet merupakan bisnis yang sangat popular dalam bidang teknologi komunikai dan informasi melalui media elektronik (komputer, gadget, telepon gegam, dll.) yang akhir-akhir ini semakin pesat perkembangannya. Jumlah pelanggan internet di seluruh Indonesia pada tahun 2016 diperkirakan sebanyak 63,6 juta dari total penduduk 256,2 juta orang. Potensi pasar jaringan internet berkembang cukup pesat seiring dengan besarnya angka pengguna komputer, gadged dan telepon gegam. Landasan teori dalam studi ini menggunakan beberapa teori umum tentang manajemen pemasaran dan teori tentang strategi bauran pemasaran khususnya yang ada kaitannya dengan bisnis internet. Studi ini lebih bersifat kasus yang menggunakan data kualitatif dan kuantitatif. Analisis data menggunakan metode deskriptif analisis Strenghts, Weaknesses, Opportunities dan Threats (SWOT) serta matriks General Electric, dan metode statistik dengan teknik Persamaan Regresi Berganda, yaitu $Y=f(X 1, X 2)$ dengan merumuskan hipotesa nihil $(\mathrm{Ho})$ dan hipotesa alternative $(\mathrm{Ha})$. Hasil studi ini menunjukkan bahwa biaya promosi dan biaya subnet/local access link corporate mempunyai pengaruh yang signifikan $(90 \%)$ terhadap total penjualan PT. Indo Internet. Sedangkan faktor lain yang berpengaruh terhadap penjualan sebesar $10 \%$. Perusahaan berada pada posisi yang menguntungkan dan dalam taraf pertumbuhan. Implikasi strategi pemasaran yang telah diterapkan oleh PT. Indo Internet sudah cukup baik, namun masih perlu dikembangkan khususnya dalam strategi distribusi (subnet), strategi promosi (iklan) dan loyalty program serta strategi pengembangan produk, sehingga pangsa pasar dapat ditingkatkan.

Kata kunci: Strategi Pemasaran, Analisis SWOT, Matriik Geneneral Electric, PT. Indo Internet
\end{abstract}

\begin{abstract}
Internet has become the current advanced technology of information and communication system. In spesific, the recent improvement of electronic media has become real evidence to support the existence of internet in modern daily life. In Indonesia, the approximization of internet users in year 2016, have reached 63.6 million over 256.2 million of population. As consequences, market potential has significantly improved accordingly. The statistic can be derived from the number of gadget and smartphone users. This study will further apply the common theoretical basis of marketing management and marketing mix in relation to internet business. Furthermore, this study will also be using both of qualitative and quantitative data. The analysis method will be using SWOT, General Electric Matrix and Statistic of Applied Linear Regression Models. The study outcome has shown significant influence of promotion costs and "subnet/local access link corporate" costs against $90 \%$ of total sales at PT. Indo Internet. Other factors have shown influence of $10 \%$ in sales. The company is in favorable position and at the stage of improvement. The application of current marketing strategy has performed good enough. However, in order to maintain continuous improvement of market shares growth, some strategical improvement will still be needed, especially in terms of distribution (subnet), promotion/advertisement, loyalty and product enhancement strategies.

Keywords : Marketing Strategy, SWOT Analysis, General Electric Matrix, PT. Indo Internet.
\end{abstract}

\section{A. Pendahuluan}

Internet merupakan kumpulan jaringan komputer yang terkait satu dengan lainnya tanpa ada penguasa atau pengatur utamanya. Jumlah pengguna internet global pada saat ini menyentuh angka 3,8 miliar dengan penetrasi 51 persen dari 
total populasi di dunia. Potensi pasar jaringan internet di Indonesia berkembang cukup pesat, besarnya potensi pasar ini dapat dengan mudah diprediksi seiring dengan jumlah pengguna computer PC/laptop, gadget dan smartphone. Laporan teranyar dari perusahaan riset pasar comScrore menunjukkan setidaknya ada 63,6 juta audiens internet atau kerap disebut "netizen" di Indonesia. Angka itu dihimpun sepanjang Januari 2017. Dari total tersebut, sebanyak 21,2 juta orang masih mengakses internet dari desktop. Sementara itu, mayoritas sudah mengakses internet via perangkat mobile seperti smartphone dan tablet, yakni sebanyak 51,7 juta orang.

Efisiensi merupakan kunci keberhasilan untuk bergerak di dunia formasi yang mengharuskan seseorang harus melakukan navigasi / manuver informasi secara cepat dan akurat, dalam hal ini internet merupakan salah satu alternatif teknologi media informasi yang memenuhi kriteria tersebut. Dari hari ke hari informasi yang dikandung dalam jaringan internet semakin lengkap, akurat dan penting. Kecepatan, kemudahan dan jangkauan informasi yang bersifat global adalah salah satu ciri teknologi komunikasi dan informasi metalui internet, sehingga media ini banyak diminati oleh masyarakat kalangan ilmuwan, para pengusaha, mahasiswa, ajar dan anggota keluarga.

\section{B. Perumusan Masalah}

Berdasarkan latar belakang penelitian, maka permasalahan dapat diidentifikasikan sebagai berikut:

1. Strategi apa yang harus dilakukan oleh PT. Indo Internet agar dapat meningkatkan pangsa pasarnya.

2. Apakah promosi (kegiatan pemasaran) dan distribusi (pengembangan subnet di daerah) yang telah dilakukan PT. Indo Internet dapat meningkatkan volume penjualan.

\section{Tujuan Penelitian}

Tujuan penelitian ini adalah untuk memberikan jawaban atas pertanyaan khusus di atas. Adapun tujuan penelitian adalah:

1. Untuk mengetahui apakah strategi pemasaran yang telah dijalankan oleh PT. Indo Unternet sudah tepat.

2. Untuk mengetahui apakah biaya promosi (pemasaran) dan distribusi (biaya subnet) berpegaruh terhadap volumen penjualan.

3. Meramalkan volume penjulan pada periode waktu mendatang. 
4. Mengembangkan strategi pemasaran PT. Indo Internet dalam meningkatkan pangsa pasar.

\section{Landasan Teori}

Banyak pengertian pemasaran yang dikemukakan oleh para ahli pemasaran, diantaranya pengertian pemasaran yang dikemukakan oleh Philip Kotler dalam buku manajemen pemasaran disebutkan bahwa "Pemasaran adalah suatu proses sosial dan manajerial dengan mana individu-individu dan elompok-kelompok mendapatkan apa yang mereka butuhkan dan inginkan melalui penciptaan, penawaran, dan pertukaran produk-produk yang bernilai".

Tempat dimana terjadi pertukaran secara umum dapat disebut dengan pasar. Pengertian pasar secara lengkap terdiri dari semua pelanggan potensial yang mempunyai kebutuhan atau keinginan tertentu yang mungkin bersedia atau dan mampu melibatkan diri dalam suatu pertukaran guna memuaskan kebutuhan atau keinginan tersebut. William J. Stanson mengemukakan pengertian pemasaran sebagai berikut: "Marketing is a total system of bussiness activities designed to plan, price, promote and distribute want satisfying goods and service to present and potential coftsumer". Maksud dari pergertian tersebut adalah bahwa pemasaran suatu sistem manajerial. Seluruh sistem kegiatan usaha harus berorientasi pada pasar/pelanggan. Pemasaran merupakan suatu proses usaha yang danamis, menyeluruh dan terpadu. Pemasaran merupakan hasil interaksi dari banyak kegiatan.

Menurut Lessar Robert Bittel "Definition of startegy is a fundamental plan of action that is intended to accomplish the companys objectives". Definisi tersebut dimaksudkan bahwa strategi adalah suatu rencana yang fundamental untuk mencapai tujuan perusahaan. Sedangkan menurut Stoner dan Freeman konsep strategi dapat didefinisikan berdasarkan dua perspektif yang berbeda yaitu yang pertama dari perspektif apa yang suatu organisasi ingin lakukan (intends to do), dan kedua dari perspektif apa yang organisasi akhirnya lakukan.

Sebelum perusahaan menentukan strategi, terlebih dahulu perusahaan harus menetapkan tujuan dari perusahaan. Dari tujuan perusahaan maka dipilihlah strategi yaitu arah untuk mencapai tujuan. Dari strategi kemudian dikembangkan menjadi taktik yaitu cara untuk mencapai tujuan. Jadi strategi pemasaran dapat diartikan suatu rencana jangka menengah yang lebih bersifat konstruktif dari suatu perusahaan untuk mencapai tujuannya dengan cara memasarkan barang atau jasa 
yang diproduksinya. Kemampuan perumusan strategi pemasaran suatu perusahaan untuk menanggapi setiap perubahan kondisi pasar tergantung pada analisis terhadap faktor faktor lingkungan; faktor pasar; persaingan; perilaku konsumen; dan analisis ekomomi dan kemampuan internal.

Philip Kotler, merumuskan pengertian bauran pemasaran sebagai berikut: "Marketing mix is the mixture of controlable marketing variables that the forms uses to pusue the sough level of sales in the target market". Definisi tersebut mengandung pengertian bahwa bauran pemesaran merupakan campuran dari variabel-variabel pemasaran yang dapat dikendalikan, dapat dipergunakan oleh suatu perusahaan untuk memperoleh tingkat penjualan yang diinginkan dalam pasar sasaran. Lebih lanjut dikemukakan bahwa bauran pemasaran terdiri dari segala hal yang dapat dilakukan perusahaan untuk mempengaruhi permintaan akan produknya yang meliputi produk, promosi, distribusi dan harga.

Produk adalah apa saja yang dapat ditawarkan ke pasar untuk diperhatikan, diperoleh, digunakan, atau dikonsumsi yang dapat memenuhi keinginan atau kebutuhan.

Agar dapat sukses dalam memasarkan suatu barang atau jasa, maka setiap perusahaan harus menetapkan harga produk secara tepat. Harga merupakan satusatunya unsur bauran pemasaran yang secara langsung memberikan pemasukan atau pendapatan bagi perusahaan. Harga merupakan komponen yang berpengaruh langsung terhadap keuntungan/laba perusahaan. Hal ini dapat dilihat dalam persamaan berikut:

1. Laba $=$ Pendapatan total - Biaya total.

2. Pendapatan total $=$ harga per unit $x$ kuantitas.

Sementara dari sudut pandang konsumen, harga sering kali digunakan sebagai indikator nilai bilamana harga tersebut dihubungkan dengan manfaat yang dirasakan atas suatu barang atau jasa. Harga akan mempengaruhi nilai dari suatu barang. Hal ini dapat dilihat pada rumus:

\section{Nilai $=\underline{\text { Manfaat yang dirasakan }}$ \\ Harga}

Jadi dapat disimpulkan bahwa pada tingkat harga tertentu, bila manfaat yang dirasakan konsumen meningkat maka nilai barang akan meningkat pula

Saluran distribusi adalah kelompok perusahaan dan perorangan yang mengambil alih hak atau membantu dalam pengalihan hak barang/jasa tertentu 
selama barang/jasa tersebut berpindah dari produsen ke konsumen. Elemenelemen distribusi dalam bauran pemasaran terdiri dari "channel of distribution, coverage, location, inventory dan transportation".

Promosi merupakan salah satu faktor penentu keberhasilan suatu program pemasaran. Batapun bagusnya suatu produk, bila masyarakat konsumen belum pernah mendengarnya dan belum yakin bahwa produk itu akan bermanfaat bagi mereka, maka mereka tidak akan membelinya. Pada hakekatnya promosi adalah semua kegiatan pemasaran yang dimaksudkan untuk menyampaikan atau mengkomunikasikan suatu produk kepada calon pelanggan.

Strategi bauran pemesaran berupaya memberikan distribusi yang optimal dari setiap metode promosi. Dalam menetukan strategi promosi tidak mudah harus dilihat dari faktor- faktor yang dapat mempengaruhinya. Berikut adalah faktor- faktor yang menentukan bauran promosi.

A. Faktor produksi

Yaitu dengan mempertimbangkan karakteristik dan cara produk itu dibeli, dikonsumsi dan dipersepsikan. Misalnya produk industri yang memerlukan pengetahuan teknis, metode personal selling dan demo lebih cocok.

B. Faktor pasar.

Bila persaingan sangat ketat, personal selling, publisitas, dan sales promotion dibutuhkan untuk mempertahankan posisi produk. Sedangkan pada pasar monopoli dan oligopoli metode iklan lebih cocok.

C. Faktor pelanggan.

Pelanggan rumah tangga lebih dapat terpikat dengan metode iklan, jika pelanggan bersifat organisasi/ instansi lebih cocok personal selling.

D. Faktor anggaran

Tergantung juga pada kondisi keuangan perusahaan. Jika perusahaan menyediakan anggaran promosi yang besar, peluangnya untuk menggunakan iklan secara nasional (melalui media TV), hadiah dan undian bisa dilakukan. Jika dana terbatas lebih memilih personal salling.

\section{Analisis SWOT}

Analisis SWOT (Strenghts, Weaknesses, Opportunities, dan Threats) adalah analisis yang dilakukan terhadap keadaan atau faktor internal perusahaan (kekuatan dan kelemahan) dan faktor eksternal perusahaan (peluang dan anacaman) yang dapat mempengaruhi operasi perusahaan. 
Dengan mengetahui basil analisis ini diharapkan perusahaan dapat menggunakan seluruh kekuatan, memanfaatkan peluang yang ada untuk mengatasi kelemahan dan ancaman yang dihadapi perusahaan. Dari hasil analisis SWOT dapat dipergunakan untuk mengetahui posisi perusahaan dan menentukan strategi pemasaran perusahaan. Dalam Modul Strategi Bisnis yang diterbitkan oleh IPWI, analisis SWOT digambarkan sebagai berikut:

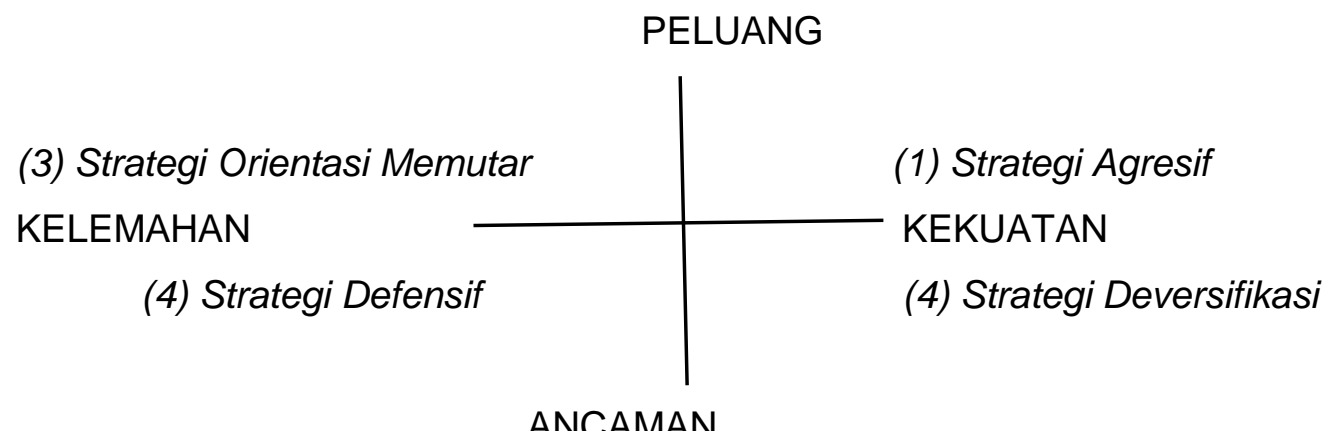

\section{Gambar 1: Diagram SWOT}

\section{Matriks General Electric}

Dalam Buku Manajemen Strategi yang disusun oleh Dr. Bambang Tri Cahyono, M.Ec. disebutkan bahwa analisis Matriks yang dikembangkan oleh General Electric, pada prinsipnya didasarkan pada analisis faktor internal perusahaan dan faktor eksternal yang mempengaruhi perusahaan. Faktor internal didefinisikan sebagai kekuatan bisnis yang melekat pada suatu perusahaan. Sedangkan faktor eksternal merupakan daya tarik suatu industri dimana perusahaan beroperasi.

Tabel 1: Faktor-faktor internal dan eksternal adalah sebagai berikut:

\begin{tabular}{|l|l|}
\hline \multicolumn{1}{|c|}{ Faktor Internal } & \multicolumn{1}{c|}{ Faktor Eksternal } \\
\hline Periklanan & Siklus penjualan \\
Panjang lini produk & Demografis \\
Pelayan konsumen & Pengahalang masuk \\
Distribusi & Isu lingkungan \\
Kekuatan keuangan & Pengahalang keluar \\
Citra produk & Konsentrasi pasar \\
Kekuatan manajemen & Pertumbuhan pasar \\
Pemabrikan & Ukuran pasar \\
Pemasaran & Isu politik \\
Pengembangan produk baru & Profitabilitas \\
\hline
\end{tabular}




\section{Pangsa pasar}

Kualitas

Perbaikan dan penunjang

Wiraniaga

Peraturan pemerintah
Ketersediaan sumber daya
Iso sosial
Keunggulan teknologi

Sumber: Hiam, 1990

Pengukuran faktor internal didasarkan pada kekuatan relatif faktor tersebut terhadap pesaing terdekatnya, sedangkan faktor eksternal diukur dari daya tarik industri atau pasar dimana perusahaan tersebut beroperasi.

Penilaian atas faktor internal dan eksternal adalah terlihat pada tabel berikut:

Tabel 2: Penilaian Faktor Internal dan Eksternal Bisnis

\begin{tabular}{|l|c|l|c|}
\hline \multicolumn{1}{|c|}{ Kekuatan Internal } & Nilai & \multicolumn{1}{|c|}{ Kekuatan Eksternal } & Nilai \\
\hline Sangat tidak bersaing & 1 & Sangat tidak menarik & 1 \\
Tidak bersaing & 2 & Tidak menarik & 2 \\
Sama kuat bersaing & 3 & Netral & 3 \\
Bersaing & 4 & Menarik & 4 \\
Sangat bersaing & 5 & Sangat menarik & 5 \\
\hline
\end{tabular}

Sumber: Hiam, 1990

Bedasarkan penilaian kedua faktor internal dan eksternal di atas, maka bisa diperoleh informasi kekuatan bisnis tinggi, sedang atau rendah, dan daya tarik industri yang tinggi, sedang, atau rendah. Gabungan antara kekuatan bisnis dan daya tarik industri akan membuahkan saran strategi perusahaan. Adapun saran strategi pada berbagai tingkat kekuatan perusahaan dapat dilihat pada table berikut.

Tabel 3: Saran Strategi Perusahaan

\begin{tabular}{|c|c|c|}
\hline $\begin{array}{l}\text { Kekuatan } \\
\text { Bisnis }\end{array}$ & $\begin{array}{c}\text { Daya Tarik } \\
\text { Industri }\end{array}$ & Saran Strategi \\
\hline Tinggi & Tinggi & $\begin{array}{l}\text { Bertumbuh, mencapai dominanasi, maksimasi } \\
\text { investasi }\end{array}$ \\
\hline Tinggi & Sedang & $\begin{array}{l}\text { Identifikasi segmen pertumbuhan, perkuat } \\
\text { Investasi, jaga posisi }\end{array}$ \\
\hline Tinggi & Rendah & $\begin{array}{l}\text { Jaga posisi keseluruhan, cari uang tunai, } \\
\text { investasi pemeliharaan }\end{array}$ \\
\hline Sedang & Tinggi & $\begin{array}{l}\text { Evaluasi kepemimpinan segmen, identifikasi } \\
\text { kelemahan, bangun kekuatan }\end{array}$ \\
\hline Sedang & Sedang & $\begin{array}{l}\text { Identifikasi segmen pertumbuhan, spesialisai, } \\
\text { investasi selektif }\end{array}$ \\
\hline Sedang & Rendah & $\begin{array}{l}\text { Kurangi lini produk, minimasi investasi, posisi } \\
\text { menarik diri }\end{array}$ \\
\hline
\end{tabular}

Vol. 1 No.3 / April 2018 


\begin{tabular}{|c|c|c|}
\hline Rendah & Tinggi & $\begin{array}{l}\text { Spesialisasi, cari ceruk pasar, pertimbangkan } \\
\text { akuisisi }\end{array}$ \\
\hline Rendah & Sedang & $\begin{array}{l}\text { Spesialisasi, cari ceruk pasar, pertimbangkan } \\
\text { keluar pasar }\end{array}$ \\
\hline Rendah & Rendah & Ikuti-pemimpin pasar, keluar, dan menarik diri \\
\hline
\end{tabular}

Sumber: Hiam, 1990

\section{E. Metodologi Penelitian}

Studi ini bertujuan untuk mengetahui ada tidaknya pengaruh variabel bebas (independent varible) terhadap variabel tidak bebas (dependent variable).

Variabel bebas dalam studi ini meliputi:

1. Biaya promosi (biaya pemasaran) yang dikeluarkan oleh PT. Indo Internet dalam kurun waktu Juli 2016 sampai dengan Desember 2017.

2. Biaya subnet yang dikeluarkan oleh PT. Indo Internet dalam kurun waktu Juli 2016 sampai dengan Desember 2017.

Sedangkan yang menjadi variabel tidak bebas dalam studi ini adalah jumlah penjualan (pendapatan) jasa layanan dalam PT. Indo Internet kurun waktu Juli 2016 sampai dengan Desember 2017.

Jenis data yang dikumpulkam meliputi:

1. Data primer, data yang diperoleh dengan cara mengajukan pertanyaanpertanyaan secara langsung kepada pejabat/karyawan perusahaan yang berwewenang/terkait.

2. Data skunder, data yang dapat diperoleh dengan cara mencatat data . statistik atau laporan-laporan perusahaan.

Disamping itu juga dilakukan studi perpustakaan untuk memberikan landasan teori dan untuk mendapatkan gambaran kondisi lingkungan industri perusahaan.

Dalam studi ini menggunakan dua metode analisis data yaitu:

1. Analisis data deskriptif dengan teknik SWOT dan teknik Matriks Generel Electric, digunakan untuk mengetahui posisi perusahaan dalam industri internet dan untuk mendapatkan saran strategi bauran pemasaran yang tepat untuk dilakukan oleh perusahaan dalam rangka perluasan usahanya.

2. Analisis data statistik teknis Regresi Berganda (multiple regression) digunakan untuk mengetahui seberapa jauh pengaruh variabel biaya promosi dan biaya subnet terhadap jumlah penjualan. 


\section{F. HASIL DAN PEMBAHASAN}

PT. Indo Internet didirikan dengan Akte Notaris Soekamini, SH Nomor 57 Tanggal 23 Maret 1994, Akte Nomor 104 Tanggal 19 Juni 1996 dan Akte Nomor 112 Tanggal 26 Desember 1996. Modal usaha perusahaan ini pada Akte Nomor 112 sebesar 5 milyar rupiah, yang seluruhnya terdiri dari 250.000 saham dengan nilai nominal 2 juta rupiah per lembar saham.

Dari modal usaha tersebut telah disetor sebanyak 1331 lembar saham yang dimiliki oleh PT. Sigma Cipta Caraka (863), Sanjaya (216), Halim Soelistio (194), Augustinus Haryawirasma (32), dan PRIMKOPPARPOSTEL (26). Pada tahun 2017 jumlah saham disetor 8.081 lembar dengan komposisi Mr. Otto Toto Sugiri (3.928), Mr. Han Arming Hanafia (1.767), Mr. Bing Moniaga (1.529), Mrs. Marina Budiman (389), Mr. Sanjaya (216), Mr. Halim Soelistio (194), Mr.Agustinus Haryawirasma (32), dan Mr.Sudjiwo Husodo (26).

PT. Indo Internet bergerak dalam bidang penyediaan jasa informasi yang menawarkan jasanya langsung kepada konsumen, ataupun bekerjasama dengan perusahaan lain yang berada di berbagai kota besar di luar Jakarta dengan kontrak kerjasama. PT. Indo Internet melayani konsumen baik secara perseorangan (individual) maupun instansi atau perusahaan (corporate \& partner).

\section{Bauran Produk dan Harga.}

Terdapat dua kelompok produk jasa internet yang ditawarkan oleh PT. Indo Internet yaitu:

a. Pelanggan Individul.

1) Quanta (free TV):

Up to $15 \mathrm{mbps}$

- 1 bulan 693.000

+ Reg 600.000 + aktivasi 1.000.000

- 6 bulan 3.950 .000 free reg + ativasi 1.000.000

- 12 bulan 8.108 .000 + aktivasi1.000.000 (Free reg, free 1 month, free wifi)

Up to $25 \mathrm{mbps}$

- 1 bulan 902.000 + Reg 600.000 + aktivasi 1 1.000 .000

- 6 bulan 5.141 .400 free reg + ativasi 1.000 .000

- 12 bulan 10.553 .400 + aktivasi1.000.000 (Free reg, free 1 month, free wifi)

Up to $50 \mathrm{mbps}$

- 1 bulan 1.573 .000

+ Reg 600.000 + aktivasi 1.000.000

Vol. 1 No.3 / April 2018 
Manajemen Pemasaran ISSN No. (PRINT) 2598-0823, (ONLINE) 2598-2893

- 6 bulan 8.966 .100

- 12 bulan 18.404 .100 wifi)

Additional TV

- 1 bulan 247.500

- 6 bulan 1.485 .000

- 12 bulan 2.970 .500

2) Ultra (Paket Internet up to)

Ultra $2 \mathrm{mbps}$ :

- 1 bulan 275.000 + Biaya registrasi 660.000

- 6 bulan 1.650.000 + Biaya registrasi 660.000

- 12 bulan 3.300.000 + Biaya registrasi 330.000

Ultra Plus 5mbps :

- 1 bulan 385.000 + Biaya registrasi 660.000

- 6 bulan 2.310.000 + Biaya registrasi 660.000

- 12 bulan 4.620 .000 + Biaya registrasi 330.000

3) Tricara (Paket internet up to + TV Channel)

Registrasi 275.000

Tricara 10

- 1 bulan 605.000

- 6 bulan 3.432 .000

- 12 bulan 7.150 .000

Tricara 25

- 1 bulan 715.000

- 6 bulan 4.092 .000

- 12 bulan 8.580 .000

Tricara 50

- 1 bulan 924.000

- 6 bulan 5.280 .000

- 12 bulan 11.088 .000

4) Tricara (Paket Internet Only Up to)

Registrasi 275.000

Tricara 20

- 1 bulan 319.000

- 6 bulan 1.815 .000

Vol. 1 No.3 / April 2018 
- 12 bulan 3.795 .000

Tricara 40

- 1 bulan 396.000

- 6 bulan 2.225 .000

- $\quad 12$ bulan 4.730 .000

Tricara 80

- 1 bulan 660.000

- 6 bulan 3.740 .000

- 12 bulan 7.865 .000

*harga sudah termasuk ppn $10 \%$

b. Copompany \& corporate

Jumlah pelanggan: 3.286

Biaya pendaftaran / Pemasangan : Custome

Biaya bulanan : Depend on product

\section{Bauran Promosi}

Direktur Utama PT. Indo Internet menyadari bahwa Pemasaran "Marketing" merupakan hal yang mendapatkan prioritas dalam pengembangan bisnisnya mengingat sudah banyaknya pesaing perusahaan yang bergerak dalam bidang yang sama. Untuk itu dia membentuk empat tim pemasaran yang terdiri dari staf pemasaran dalam usaha meningkatkan usahanya. Keempat tim pemasaran tersebut bertanggung jawab sepenuhnya terhadap penambahan pelanggan baru.

Kegiatan dari tim pemasaran tersebut yaitu:

a. Mempelajari keadaan pasar potensial baik dari kelompok individual maupun instansi/perusahaan.

b. Menyusun perencanaan pemasaran serta langkah langkahnya.

c. Melakukan promosi paket produk yang sudah siap ditawarkan.

Kegiatan promosi dilakukan secara terus menerus untuk mencapai target pendapatan yang telah ditentukan. Ada beberapa hambatan yang dilakukan dalam promosi diantaranya adalah:

- Besarnya biaya promosi melalui mass media / media elektronik.

- Bayaknya perusahaan pesaing yang telah melakukan usaha sebagai penyedia jasa internet dan TV kabel.

- Masyarakat sudah banyak yang dapat melakukan akses internet melalui gadget dan atau telepon genggam. 
- Sistem pengadaan jasa internet instansi pemerintah dan BUMN diharuskan melalui pelelangan.

- Dengan tarif paling rendah Rp319.000,- per bulan dirasakan masih berat untuk kalangan masyarakat kelas menengah ke bawah.

Pelaksanaan promosi jasa internet oleh PT. Indo Internet yang telah dilakukan dengan cara:

1) Entertainment

Anggaran biaya yang terserap untuk kegiatan entertainment periode Januari 2017 s.d. Desember 2017 sebesar Rp280.318.750,- atau 33,64\% dari anggaran biaya pemasaran.

2) Advertising \& Promotion

Anggaran biaya yang terserap untuk kegiatan advertising \& promotion periode Januari 2017 s.d. Desember 2017 sebesar Rp475.058.824,- atau 57,00\% dari anggaran biaya pemasaran.

3) Loyalty program

Tidak ada biaya untuk kegiatan pembayaran loyalty program atau $0 \%$ dari anggaran biaya pemasaran.

4) Research \& Development

Anggaran biaya yang terserap untuk kegiatan research \& development periode Januari 2017 s.d. Desember 2017 sebesar Rp78.000.000,- atau 9,36\% dari anggaran biaya pemasaran.

5) Others

Tidak ada biaya untuk kegiatan biaya pemasaran lainnya atau 0\% dari anggaran biaya pemasaran.

\section{Bauran Distribusi}

Dalam memperluas pangsa pasar PT. Indo Internet memilih cara bekerja sama dengan beberapa perusahaan lain yang bergerak dalam bidang internet di berbagai daerah luar Jakarta (23 kota) yang disebut dengan Subnet. Dalam kontrak kerjasama PT. Indo Internet menyediakan fasilitas internet, dan perusahaan mitra kerjanya mencari pelanggan di wilayah usahanya dengan sistem bagi hasil.

\section{Analisis Data}

Analisis kekuatan dan kelemahan (Faktor Intern).

Kekuatan: 
- PT. Indo Internet mempunyai nasabah yang cukup besar, pelanggan individual sebanyak 4.946, dan pelanggan corporate sebanyak 3.826.

- Adanya dukungan dari mitra kerja perusahaan lain di berbagai daerah dalam pengoperasian jasa internet.

- Komitmen pimpinan perusahan sangat tinggi dalam pengembangan usahanya dan menyadari bahwa pentingnya bidang pemasaran.

Kelemahan:

- Kurangnya modal usaha untuk melakukan pengembangan jaringan internet di berbagai daerah.

- Kurangnya SDM yang handal dan belum optimalnya kinerja organisasi perusahaan khususnya pada devisi pemasaran.

Analisis peluang dan ancaman (Faktor Eksternal).

Peluang:

- Perkembangan teknologi informasi menunjukkan makin semaraknya masyarakat berkomunikasi melalui jasa internet.

- Adanya dukungan dari pemerintah bahwa masyarakat Indonesia harus siap dalam menghadapi era globalisasi khususnya dalam bidang informasi.

- Meningkatnya masyarakat yang telah memiliki peralatan komputer dan jaringan telpon akan menambah pangsa pasar.

Ancaman:

- Banyaknya perusahaan lain yang bergerak balam bidang penyedia jasa internet (67 perusahaan) merupakan pesaing dan ancaman perusahaan dalam kelangsungan usahanya.

- Perkembangan teknologi komputer sangat cepat, sehingga kemungkinan munculnya teknologi informasi baru dapat menggeser peranan internet dalam bidang informasi.

Dari analisis SWOT di atas dapat disimpulkan bahwa kekuatan perusahaan lebih dominan dari pada kelemahan dan perusahaan lebih banyak mendapatkan peluang dari pada ancaman sehingga posisi bisnis PT. Indo Internet berada pada kuadran (1). Pada posisi inisituasi perusahaan menguntungkan, dan disarankan untuk menerapkan strategi agresif untuk pertumbuhan.

Jika digambarkan dengan analisis SWOT posisi bisnis PT. Indo Internet adalah sebagai berukut: 
Manajemen Pemasaran ISSN No. (PRINT) 2598-0823, (ONLINE) 2598-2893

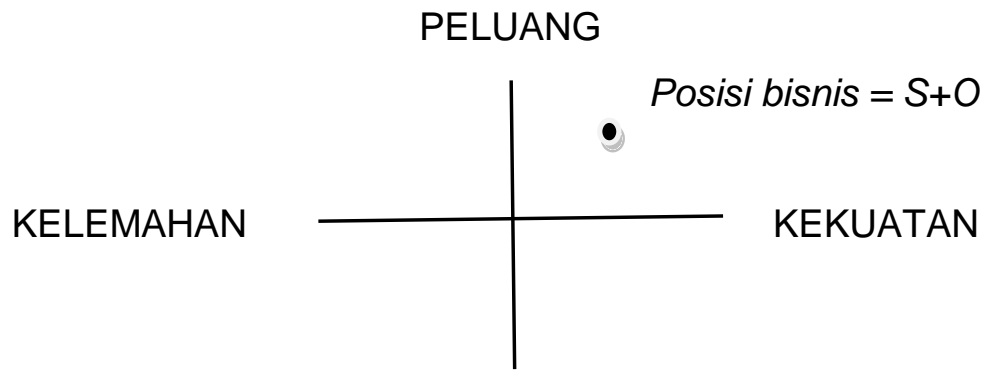

ANCAMAN

\section{Gambar 2:}

\section{Posisi PT. Indo Internet dalam Analisis SWOT}

\section{Matriks General Electric}

Kekuatan bisnis (faktor internal) dan daya tarik industri (faktor eksternal) PT. Indo Internet serta pembobotannya adalah sebagai berikut.

Tabel 4: Faktor Internal dan Faktor Eksternal PT. Indo Internet

\begin{tabular}{|l|c|l|c|}
\hline \multicolumn{1}{|c|}{ Faktor Internal } & Bobot & \multicolumn{1}{|c|}{ Faktor Eksternal } & Bobot \\
\hline Pemasaran & 3 & Ekonomi & 4 \\
Sumber Daya Manusia & 3 & Sosial & 4 \\
Keuangan & 4 & Budaya & 3 \\
Produksi & 5 & Kebijakan Pemerintah & 5 \\
\hline Rata-rata & 3,75 & & 4 \\
\hline
\end{tabular}

Sumber: hasil analisis

Dari tabel di atas dapat disimpulkan bahwa rata-rata bobot faktor internal 3.75 dan faktor eksternal 4. Kekuatan bisnis yang diperoleh dari faktor internal adalah tinggi, sedangkan daya tarik perusahaan yang diperoleh dari faktor ekternal yang relevan terhadap industri internet juga tinggi. Jadi saran strategi yang perlu dilakukan oleh PT. Indo Internet adalah pertumbuhan untuk mencapai dominasi, dan memaksimasi investasi.

\section{Analisis Statistik}

Berikut disajikan data perkembangan perusahaan yang dilihat dari segi jumlah penjualan per bulan, biaya pemasaran (promosi) dan biaya subnet yaitu biaya yang dikeluarkan untuk menunjang kegiatan internet di daerah. 
Tabel 5: Perkembangan Penjualan PT. Indo Internet

Periode Juli 2016 s.d. Desember 2017

\begin{tabular}{|c|l|r|r|r|}
\hline No & \multicolumn{1}{|c|}{ Bulan } & $\begin{array}{c}\text { Penjualan } \\
\text { (Rp000) }\end{array}$ & $\begin{array}{r}\text { Biaya Promosi } \\
\text { (Rp000) }\end{array}$ & $\begin{array}{r}\text { Biaya Subnet } \\
\text { (Rp000) }\end{array}$ \\
\hline 1 & Juli 2016 & $10,672,231$ & 55,629 & $1,182,114$ \\
2 & Agustus & $10,706,941$ & 52,604 & $1,130,900$ \\
3 & September & $10,790,269$ & 59,591 & $1,267,181$ \\
4 & Oktober & $10,605,524$ & 63,990 & $1,049,727$ \\
5 & November & $11,517,922$ & 61,638 & $1,176,005$ \\
6 & Desember & $13,848,862$ & 70,355 & $1,187,472$ \\
7 & Januari 2017 & $12,228,879$ & 64,715 & $1,271,165$ \\
8 & Februari & $11,919,825$ & 64,080 & $1,133,114$ \\
9 & Maret & $11,858,256$ & 62,754 & $1,102,115$ \\
10 & April & $12,389,015$ & 64,563 & $1,299,070$ \\
11 & Mei & $12,397,232$ & 65,606 & $1,250,291$ \\
12 & Juni & $12,293,200$ & 64,056 & $1,230,836$ \\
13 & Juli & $12,343,767$ & 66,323 & $1,310,929$ \\
14 & Agustus & $12,190,032$ & 64,510 & $1,297,848$ \\
15 & September & $12,877,454$ & 66,148 & $1,363,764$ \\
16 & Oktober & $13,009,098$ & 70,844 & $1,280,118$ \\
17 & November & $13,799,376$ & 83,026 & $1,365,971$ \\
18 & Desember & $20,172,220$ & 96,753 & $1,782,182$ \\
\hline & Jumlah & $225,620,103$ & $1,197,185$ & $22,680,802$ \\
\hline
\end{tabular}

Sumber: Diolah dari Income Statement PT. Indo Internet 2016 - 2017

$Y$ $=$ variabel dependent (pendapatan jasa)

X1 dan X2 = variabel independen (biaya promosi dan biaya subnet)

Dengan menggunakan teknik analisis regresi berganda diperoleh hasil sebagai berikut:

SUMMARY OUTPUT

\begin{tabular}{|c|c|c|c|c|}
\hline \multicolumn{3}{|c|}{ Regression Statistics } & & \\
\hline Multiple R & & 0.955053351 & & \\
\hline R Square & & 0.912126903 & & \\
\hline Adjusted R Square & & 0.90041049 & & \\
\hline Standard Error & & 675069.9529 & & \\
\hline Observations & & 18 & & \\
\hline \multicolumn{5}{|l|}{ ANOVA } \\
\hline & $d f$ & $S S$ & $M S$ & $F$ \\
\hline Regression & 2 & $7.09558 E+13$ & $3.54779 \mathrm{E}+13$ & 77.8503546 \\
\hline Residual & 15 & $6.83579 E+12$ & $4.55719 \mathrm{E}+11$ & \\
\hline Total & 17 & $7.77916 \mathrm{E}+13$ & & \\
\hline
\end{tabular}


Manajemen Pemasaran ISSN No. (PRINT) 2598-0823, (ONLINE) 2598-2893

\begin{tabular}{|c|c|c|c|c|}
\hline & & Standard & & \\
\hline & Coefficients & Error & t Stat & $P$-value \\
\hline & - & & - & \\
\hline Intercept & 2921081.644 & 1320127.047 & 2.212727669 & 0.042841301 \\
\hline X Variable 1 & 132.8064354 & 29.08914691 & 4.56549777 & 0.000371575 \\
\hline X Variable 2 & 5.255797403 & 1.818156084 & 2.890729486 & 0.011203285 \\
\hline
\end{tabular}

a. Fungsi Regresi

Fungsi regresi yang diperoleh:

$\mathrm{Y}=-2921081.644+132.81 \mathrm{X} 1+5.26 \mathrm{X} 2$

t-statistic $\quad-2.212 \quad 4.565 \quad 2.890$

b. Koeefisien Determinasi

R-squared $=0.900$ ini berarti bahwa $90 \%$ penjualan PT. Indo Internet dipengaruhi oleh biaya Promosi dan biaya Subnet. Sedangkan sisanya (10\%) disebabkan oleh faktor lain yang tidak dimasukkan dalam studi ini.

c. Uji Kooefisien Regresi Parsial

1) Penentuan alpha.

Dengan menggunakan alpha $(\alpha)=0.5 \quad$ (level of significant $=5 \%$ ) atau $\alpha / 2=0.25$, pada derajat kebebasan $(\mathrm{df})=15(\mathrm{n}-3)$, maka diperoleh $\mathrm{t} \alpha / 2=$ 2.131 (lihat tabel t distribusi).

2) Kesimpulan.

$$
\begin{aligned}
& \text { to }, \mathrm{X} 1=4.565>\mathrm{ta} / 2=2.131 \\
& \text { to, } \mathrm{X} 2=2.890 \quad>\mathrm{ta} / 2=2.131
\end{aligned}
$$

Dari hasil tersebut dapat disimpulkan bahwa Ho ditolak dan Ha diterima jadi dengan tingkat kepercayaan 95\%, dapat dikatakan bahwa terdapat pengaruh yang signifikan antara variabel biaya promosi dan biaya subnet dengan besarnya penjualan pada PT. Indo Internet dalam kurun waktu Juli 2016 sampai Desember 2017

d. Uji Regresi secara menyeluruh

1) Penentuan alpha.

Dengan menggunakan alpha $(\alpha)=0.5 \quad$ (level of significant $=5 \%$ ) pada derajat kebebasan $(\mathrm{df})=2 ; 15$, maka diperoleh $\mathrm{Fa}=3.68$ (lihat tabel $\mathrm{F}$ distribusi).

2) Kesimpulan

Fo $=77.85>\mathrm{Fa}=3.68$, jadi kesimpulannya bahwa $\mathrm{Ho}$ ditolak dan $\mathrm{Ha}$ diterima; jadi persamaan regresi tersebut diatas $(Y=a+b 1 X 1+b 2 X 2)$ dapat diterima dan dapat digunakan untuk meramalkan besarnya penjualan pada periode mendatang. 


\section{G. Kesimpulan dan Saran}

Dari hasil studi dan pembahasan yang menyangkut strategi bauaran pemasaran PT. Indo Internet untuk meningkatkan penjualan dan pangsa pasar maka dapat disimpulkan sebagai berikut:

1. Berdasarkan hasil analisis SWOT dan Matriks General Electric menunjukkan bahwa perusahaan cenderung berada pada posisi yang menguntungkan. Kekuatan relatif bisnis PT. Indo Internet tinggi dan daya tarik industri tinggi. Daur hidup produk perusahaan pada taraf pertumbuhan dan perlu diperluas usahanya. Hal ini didukung makin semaraknya penggunaan internet dalam era globalisasi informasi.

2. Berdasarkan analisis statistik terbukti bahwa tingkat penjualan PT. Indo Internet relatif meningkat. Hasil pengujian hipotesa menunjukkan bahwa biaya promosi dan biaya subnet secara signifikan mempengaruhi tingkat penjualan. Jumlah penjualan dipengaruhi oleh biaya promosi dan biaya subnet sebesar $90 \%$, sedangkan sisanya (10\%) dipengaruhi oleh faktor-faktor lain yang tidak dimasukkan dalam studi ini.

\section{H. Saran}

Dari uraian pada hasil studi dan pembahasan serta kesimpulan di atas, maka dapat disarakan sebagai berikut:

1. Strategi bisnis yang disarankan dalam studi ini adalah bahwa PT. Indo Internet yang bergerak dalam bidang penyediaan jasa internet perlu melakukan perluasan bisnis, sehingga dapat mencapai dominan (kedewasaan) dengan cara memaksimasi investasi.

2. Kegiatan promosi perlu terus dilakukan secara intensif khususnya kepada pelanggan individu. Kegiatan promosi hendaknya lebih bersifat menarik konsumen dan menjangkau masyarakat kelas menengah ke bawah. Promosi berupa iklan perlu ditingkatkan mengingat dari pengamatan masih banyak masyarakat yang tidak mengenal Indo Internet (Indonet).

3. Distribusi (subnet) terus diperluas secara intensif bahkan jika memungkinkan tidak sekedar bekerjasama dengan perusahaan lain dalam pengoperasian internet di daerah, tetapi perlu mendirikan kantor-kantor cabang yang secara langsung dapat dikendalikan oleh perusahaan.

4. Inovasi paket produk internet agar terus dilakukan sehingga dapat melayani berbagai macam segmen pasar kususnya untuk kalangan mahasiswa, pelajar dan para buruh. 
Manajemen Pemasaran ISSN NO. (PRINT) 2598-0823, (ONLINE) 2598-2893

\section{DAFTAR PUSTAKA}

Basu Swastha Dharmmessta, Prof. Dr., Manajemen Pemasaran, Buku Materi Pokok Universitas Terbuka, Penerbit Universitas Terbuka, Edisi 2, 2016.

Mamduh Hanafi, Dr., Manajemen, Buku Materi Pokok Universitas Terbuka, Penerbit Universitas Terbuka, Edisi 2, 2016.

Kotler Philip, Manajemen Pemesaran, Implementasi, dan Pengendalian, Penerbit Salemba Empat, Analisis, Perencanaan, Edisi Bahasa Indonesia Jakarta, 1995.

Warren J. Keegan, Manajemen Pemasaran Global, Edisi Bahasa Indonesia Kelima, Prenhallindo, Jakarta, 1996.

Modul IPWI, Strategi Bisnis Program Pasca Sarjana Magister Manajemen, Badan Penerbit IPWI, 1995.

Modul IPWI, Manajemen Pemasaran, Program Pasca Sarjana Magister Manajemen, Badan Penerbit IPWI, 1995.

Agus Sunyoto, Dr., Prakiraan Bisnis, Modul Program Pasca Sarjana Magister Manajemen, Badan Penerbit IPWI, 1995.

Fandy Tjiptono, Strategi Pemasaran, Adni Offset, Yogyakarta, 1995.

J. Supranto, M.A., Teknik Riset Pemasaran dan Ramalan Usaha, Rineka Cipta, Jakarta, 1990.

Porter, Michael E, Competetive Strategy Tecnigues for Analizinq Industris and Competetive, The Free Press, New York, 1980.

Bambang Tri Cahyono, Ph.D, Manajemen Strategi Analisis Bisnis Nasional dan Multinasional, STIE IPWI.

Bambang Tri Cahyono, Ph.D, Revolosi Pemasaran, Badan Penerbit IPWI, 1995.

Bambang Tri Cahyono, Ph.D, Manajemen Pemasaran Analisis Agribisnis dan Industri, STIE IPWI.

Cornelis Rintuh, Dr., Metodologi Penelitian Ekonomi, Liberty, Yogyakarta, 1994.

Hosni Suradji, Dr., Bahan Kuliah Manajemen Pemasaran, Program Magister Manajemen, STIE IPWI, 1995. 
Manajemen Pemasaran ISSN No. (PRINT) 2598-0823, (ONLINE) 2598-2893

J. Supranto, M.A., Bahan Kuliah Riset Pemasaran, Program Magister Manajemen, STIE IPWI, 1996.

Soeratno, M.Ec, Lincolin Arsyad, M.Sc., Metodologi Penelitian Untuk Ekonomi dan Bisnis, UPP AMP YKPN, 1993. 